\title{
Prospective on Different Approaches for Vaccine Development Against COVID-19: Past Lessons and Future Challenges
}

\author{
Rahimi Pooneh ${ }^{1,2}$, Aghasadeghi Mohammd Reza ${ }^{1,2}$ \\ ${ }^{1}$ Department of Hepatitis and AIDS, Pasteur Institute of Iran, Tehran, Iran. ${ }^{2}$ Viral Vaccine Research Center (VVRC), Pasteur \\ Institute of Iran, Tehran, Iran
}

\begin{tabular}{|c|c|}
\hline A R T I C L E I N F O & A B S T R A C T \\
\hline $\begin{array}{l}\text { Review Article } \\
\text { VacRes, 2019 } \\
\text { Vol. 6, No.2, 14-17 } \\
\text { Received: March 02, } 2020 \\
\text { Accepted:May 06, 2020 } \\
\text { Pasteur Institute of Iran } \\
\text { *Corresponding Author: Rahimi } \\
\text { Pooneh. Department of Hepatitis and } \\
\text { AIDS, Pasteur Institute of Iran, } \\
\text { Tehran, } \\
\text { Email: pooneh5376@yahoo.com } \\
\text { Tel/Fax: +2166969291 }\end{array}$ & $\begin{array}{l}\text { Since the reemergence of a severe acute respiratory syndrome caused by a novel } \\
\text { coronavirus (SARS-CoV-2), the disease caused by this virus, known as COVID-19, has } \\
\text { been spreading rapidly all around the world. As of early June 2020, COVID-19 has } \\
\text { infected more that } 6.6 \text { million people, and has caused more than } 390,000 \text { deaths, globally. } \\
\text { Similar to its pioneers, namely SARS-CoV and MERS-CoV, there is currently no vaccine } \\
\text { or specific antiviral treatment against this virus. This review provides a timely overview on } \\
\text { efforts as well as different platforms used for developing an effective vaccine against } \\
\text { COVID-19. }\end{array}$ \\
\hline $\begin{array}{l}\text { KEYWORDS: SARS-CoV-2, } \\
\text { COVID-19, Spike protein, subunit } \\
\text { vaccines, COVID-19 vaccines }\end{array}$ & $\begin{array}{l}\text { Citaion: } \\
\text { Rhimi P, Aghasadeghi M R. Prospective on Different Approaches for Vaccine Development } \\
\text { Against COVID-19: Past Lessons and Future Challenges. vacres. 2019; } 6 \text { (2) :14-17. DOI: } \\
\text { 10.29252/vacres.6.2.14 }\end{array}$ \\
\hline
\end{tabular}

\section{INTRODUCTION}

The pandemic due to a novel severe acute respiratory syndrome, named COVID-19, caused by an emerging coronavirus; SARS-CoV-2, is the worst health challenge of the new millennium. Coronaviridae are enveloped viruses, known as the largest RNA viruses which contain a single-stranded positive-sense RNA genome ( $30 \mathrm{~kb})$ with 5 '-cap structure, and 3'-poly-A tail. The virion envelope of $\mathrm{CoVs}$ contains at least three structural proteins, S, E, and $\mathrm{M}$, embedded in the membrane [1,2]. SARS-CoV-2 has been classified in Orthocoronavirinae sub-family, and Betacoronovirus genera which also includes SARS-CoV, the causative agent of severe acute respiratory syndrome (SARS), and MERS-CoV that caused the Middle East respiratory syndrome (MERS) [1,2]. The genome of SARS-CoV-2 consists of at least six ORFs. The $5^{\prime}$ two-thirds of the genome contains two ORFs (ORF1a/b) that encode 16 non-structural proteins and contain about two-thirds of the whole genome's length. The translation of each ORF results in production of related polyproteins that need to be processed by viral proteases such as viral chymotrypsin-like (3CLpro), main protease (Mpro) and papain-like proteases, into 16 non-structural proteins [1,2]. Some of these non-structural proteins function in virus replication and the roles of the others have not yet been understood [3]. The structural proteins, namely spike $(\mathrm{S})$, nucleocapcid $(\mathrm{N})$, membrane $(\mathrm{M})$, and envelope (E) are encoded by their related ORFs, located near the 3 -terminus of the genome [3]. Studies on the genome sequences have revealed that the non-structural proteins are more conserved in comparison with the structural proteins that are highly variable [3]. Most members of this family, including SARS-CoV-2 are zoonotic, thus have a wide variety of natural hosts such as bats which enable them for genetic reassortment and recombination, leading to diversity in their viral structural proteins (i.e. N, M, E, S), as well as increase in their ability for adaptation to new hosts; hence, breaking the species barrier [3].

It is known that SARS-CoV-2 is transmitted from the infected individuals without symptoms during the incubation period of approximately 14 days. This makes the virus capable of quickly spreading in human societies, leading to a pandemic situation within few weeks with clinical manifestations diversities in different countries. Therefore, the control of COVID-19 without an efficient vaccine will be the most challenging public health problem in modern history. Since the beginning of SARS-CoV-2 outbreak, many studies have been conducted to understand the characteristics of this virus such as its pathogenesis and the immune responses against it, in order to design an effective vaccine. So far, there is only limited data available about COVID-19 vaccine candidates that are currently under evaluations and in clinical trials in several countries. Herein, the available public information on this issue is briefly reviewed. 


\section{Structural Proteins as the Vaccine Candidates}

The first attractive candidates for designing an antiviral vaccine are the structural proteins of that virus, especially those with abilities to induce the immune responses. The structural proteins are important for cellular infection and virion assembly. The first step of a cell infection is viral attachment to the host's cellular receptor/s $[3,4]$. Although E protein is a minor component of the virus membrane, it plays an important role in many stages of the virus infection and replication [5]. Studies have shown that in SARS-CoV-2, E protein is very similar to its counterparts such as in Bat and Pangolin coronavirus isolates. However, SARS-CoV-2 E protein possesses specific substitutions such replacement of Arg amino acid by Glu or Gln, and modifications at the C-terminal followed by a unique deletion [5].

The $\mathrm{E}$ protein in SARS-CoV-2 functions in virus assembly and release and is involved in viral pathogenesis; however, it is not essential for the viral replication [6,7]. It has been found that the lack of $\mathrm{E}$ gene results in the attenuated viruses which still could replicate in hamsters. This finding suggests that E-deficient coronaviruses should be considered as a safer research tool for developing a live-attenuated vaccine [1]. The $\mathrm{M}$ protein is bound to the nucleocapcid and is responsible for the virus budding and also for the curvature shape of the viral membrane [8, 9]. The $\mathrm{N}$ protein (nucleoprotein) encapsidates the viral genome. It is a $46-\mathrm{kDa}$ protein, composed of 422 amino acids which contains positively-charged amino acids at the $\mathrm{N}$ terminal that binds to the viral RNA. The $\mathrm{N}$ protein undergoes different posttranslational modifications such as phosphorylation, acetylation and sumoylation. Sumoylation is a process that modifies a target protein, post-translationally with small ( 12 kDa) ubiquitin-like proteins, called SUMOs. Sumylation of the N protein renders its abilities for nucleocytoplasmic transport, transcriptional regulation, apoptosis and regulation of the cell cycle proteins [10]. This protein is composed of two independent structural domains, namely $\mathrm{N}$ and $\mathrm{C}$ terminals, and a linker region located between these two domains that interacts with the membrane $(\mathrm{M})$ protein $[9,10]$. This protein interferes with different cellular pathways, thus can be considered as a regulatory protein. The $\mathrm{N}$ protein is expressed at the early stage of SARS-CoV-2 infection, and the immune responses against it results in antibody rising in a few days after the infection. Therefore, the $\mathrm{N}$ protein is an attractive diagnostic tool for serological tests such as ELISA [11].

The spike glycoprotein $(180 \mathrm{kDa})$ is embedded in the viral envelope as homotrimers, performing the viral attachment to the cellular receptor/s [3,4,12]. They composed of two subunits, namely S1 and S2, with a furin cleavage site at the boundary between the $\mathrm{S} 1 / \mathrm{S} 2$ subunits. This specific cleavage is processed during biogenesis and makes SARS-CoV-2 a unique virus apart from its former CoVs (i.e. SARS-CoV and MERS$\mathrm{CoV})$ [13]. The $\mathrm{S} 1$ subunit is responsible for the receptor binding and is divided into two sub-domains: the N-terminal subdomain (NTD) that binds to sialic acid and is very divergent, and the C-terminal subunit (CTD) which binds to a specific proteinaceous receptor and is more conserved compared to the NTD [14]. The CTD of S1 subunit interacts with the human angiotensin convertor enzyme-2, known as ACE2 (hACE2) with comparable affinity to SARS-CoV. This tight binding to hACE2 could partially explain the efficient transmission of SARS-CoV-2 in humans $[13,15]$. However, the exact region in SARS-CoV-2 S1 protein that is responsible for hACE2 binding remains unknown [16]. The S2 subunit contains a transmembrane and a cytoplasmic domain. It functions as a fusion peptide and is highly conserved that makes it an important target for the antiviral (anti-S2) compounds. Up to now, WHO has identified more than 60 vaccine candidates which are being investigated against SARSCoV-2 virus across a range of platforms such as nucleic acid, live-attenuated, protein subunit, and viral vector. Amongst them, 2 candidates are being undergone for the phase 1 of clinical trials, while the remaining candidates are preclinical [17].

Table 1. Number of vaccine candidates that are being currently investigated for COVID-19 [17].

\begin{tabular}{|c|c|}
\hline Platform & Number of vaccine candidates \\
\hline DNA & 5 \\
\hline RNA & 3 \\
\hline Inactivated & 2 \\
\hline Live- attenuated & 8 \\
\hline Non-replicating viral vector & 23 \\
\hline Protein subunit & 5 \\
\hline Replicating viral vector & 2 \\
\hline Virus -like particle & 6 \\
\hline Unknown or other & $\mathbf{6 3}$ \\
\hline Total & \\
\hline
\end{tabular}

\section{Types of Vaccine Candidates Against COVID-19}

A- Whole virus vaccines

These vaccines contain a live-attenuated or an inactive whole virus. They represent a classic strategy for viral vaccinations such as human rabies vaccine (inactivated rabies virus), animal rabies vaccine (live-attenuated rabies virus), and oral polio vaccine (OPV; live-attenuated polio virus) [16,17]. Whole virus vaccines have some important advantages in inducing the immune response due to their ability to be recognized through interaction with toll-like receptors (TLRs) such as TLR3,7,8, and 9 [18]. However, developing a live virus vaccine is challenging and requires extensive biosafety testing. Johnson \& Johnson Company has an impressive experience in developing an Ebola vaccine, named Janssen's AdVac $\mathbb{R}$ adenoviral vector, produced using their PER.C6 ${ }^{\circledR}$ cell line technology. According to the satisfying results of $A d V a c \circledR$, this company has been developing a protective COVID-19 vaccine, based on their previous improved technology [19,20]. At The University of Hong Kong, a live influenza vaccine that expresses SARS-CoV-2 proteins has been developed [21]. In addition, Codagenix has developed a new strategy for attenuated SARS-CoV-2 by using "codon deoptimization" technology [22].

It should be noted that using whole virus vaccines as liveattenuated or killed viruses which have been developed against SARS-CoV, have resulted in increased infectivity [18,23]. The enhanced disease phenomenon has been previously recognized in some vaccines containing whole/ live- attenuated or killed 
viruses, such as respiratory syncytial virus (RSV) vaccine due to eliciting eosinophilic infiltration and immuno-enhancing pathology. Moreover, in the case of whole-virus SARS-CoV vaccine, Th2-mediated inflammatory alveolar damage in laboratory animals which had been vaccinated with whole SARS-CoV virus vaccine and challenged subsequently with the infectious virus, has been reported [23].

\section{B- Subunit Vaccines}

The main viral protein used for developing a subunit vaccine against SARS-CoV was its spike protein which could elicit a sufficient immune response to prevent the $S$ protein from binding to the host cellular receptor (ACE2) [18]. In an attempt conducted by University of Queensland (Australia), in order to facilitate the recognition of the viral surface antigen and better induction of the immune response, the $\mathrm{S}$ protein has been synthesized, and presented to the immune system [18]. Clover Biopharmaceuticals (China) is using their patented trimer $-\operatorname{tag} ®$ technology to conduct a project for developing a subunit vaccine containing a trimerized SARS-CoV-2 S protein [24]. Due to the increased virulence in evaluation of some vaccine candidates comprised of full-length $S$ proteins for SARS, University of Texas Medical Branch and New York Blood Center in the United States are collaborating in developing a subunit vaccine which consists of only the receptor-binding domain (RBD) of the SARS-CoV S protein $[18,25,26]$. The Academy of Military Medical Sciences (China) has developed a subunit vaccine which has put it into clinical trials after approval.

\section{C- Nucleic Acid Vaccines}

Using nucleic acids as a vaccine developing technology has been pursued for several years. Recently, improvements on knowledge about the immune system has led to implementation of new modifications and formulations in vaccine design studies which could be used in producing effective nucleic acid based vaccines [27,28,29]. Although it has been shown that DNA vaccines can efficiently induce both the humoral and the cell-mediated immune responses in animal models, promising immunogenic responses in humans have not yet been achieved $[29,30]$. After the recent pandemic, some renowned vaccine producing companies have started working on vaccine development against COVID-19 through this pipeline. For example, Inovio Pharmaceuticals (USA) is exploring a DNA vaccine. Meanwhile, Moderna Therapeutics (USA) and CureVac (Germany) are working on developing RNA vaccine platforms. This mRNA vaccine called mRNA-1273 encodes for a stable form of the SARS-CoV-2 spike protein which was rapidly developed and became ready for clinical trials in humans [31,32]. The mRNA vaccines carry the coding sequences of the proteins which basically mimic the natural infection of the virus. However, they contain only a short synthetic version of the viral mRNA which encodes only the antigen protein. In contrast to standard vaccines with the viral to immunize, an mRNA vaccine can be translated inside the patient's cells to produce the viral proteins. They are not able to integrate into the genome of the recipients and are safer, compared to whole virus vaccines such as the live-attenuated or the killed ones as well as the DNA vaccines. These vaccines could bypass the hassles of producing pure viral proteins; therefore, can save time for their mass productions, especially during the pandemic. Generally, previous studies on developing vaccines against SARS-CoV and MERS-CoV have elucidated the high level of neutralizing antibody which could be achieved by using the viral $\mathrm{S}$ protein subunit vaccines (i.e. RNA-based vaccine encoding viral $S$ protein, compared to DNA-based $S$ protein vaccines, full-length $\mathrm{S}$ protein and live-attenuated SARS-CoV [33,34,35,36,37,38].

In conclusion, there are now several vaccine candidates that are being evaluated against COVID-19 while each of them requires additional manufacturing steps before being available for the public use. The RNA vaccine platform seems to be promising for developing an efficient vaccine against SARSCoV-2 infection. Until the availability of a reliable vaccine, social distancing and vigilance remain the best options in fight against COVD-19.

\section{CONFLICT OF INTEREST}

The author declares that there is no conflict of interest.

\section{REFERENCES}

1. DeDiego ML, Alvarez E, Almazan F, et al. A severe acute respiratory syndrome coronavirus that lacks the $\mathrm{E}$ gene is attenuated in vitro and in vivo. J Virol. 2007;81(4):1701-1713. DOI: 10.1128/JVI.01467-06.

2. Nieto-Torres JL, DeDiego ML, Verdiá-Báguena C, et al. Severe acute respiratory syndrome coronavirus envelope protein ion channel activity promotes virus fitness and pathogenesis. PLOS Pathog. 2014;10(5):e1004077. doi: 10.1371/journal.ppat.1004077.

3. Chen Y, Liu Q, Guo D. Emerging coronaviruses: Genome structure, replication, and pathogenesis. J Med Virol. 2020; 92:418-423. DOI: 10.1002/jmv.25681.

4. Nal B. Differential maturation and subcellular localization of severe acute respiratory syndrome coronavirus surface proteins S, M and E. J Gen Virol. 2005;86(Pt 5):1423-1434. DOI: 10.1099/vir.0.80671-0.

5. Schoeman D, Fielding BC. Coronavirus envelope protein: current knowledge. Virol J. 2019;16(69):1-22. https://doi.org/10.1186/s12985-0191182-0.

6. DeDiego ML, Alvarez E, Almazan F, et al. A severe acute respiratory syndrome coronavirus that lacks the $\mathrm{E}$ gene is attenuated in vitro and in vivo. J Virol. 2007;81(4):1701-1713. DOI: 10.1128/JVI.01467-06.

7. Nieto-Torres JL, DeDiego ML, Verdiá-Báguena C, et al. Severe acute respiratory syndrome coronavirus envelope protein ion channel activity promotes virus fitness and pathogenesis. PLOS Pathog. 2014;10(5):e1004077. doi: 10.1371/journal.ppat.1004077.

8. Neuman BW, Kiss G, Kunding AH, et al. A structural analysis of M protein in coronavirus assembly and morphology. J Struct Biol. 2011;174(1):11-22. doi: 10.1016/j.jsb.2010.11.021. 9.Alsaadi EAJ, Jones I M. Membrane binding proteins of coronaviruses. Future Virology 2019; 14(4), 275-286. https://doi.org/10.2217/fvl-2018-0144.

10. Li YH, Li J, Liu XE, Wang L, Li T, Zhou YH, Zhuang H. Detection of the nucleocapsid protein of severe acute respiratory syndrome coronavirus in serum: comparison with results of other viral markers. J Virol Methods. 2005; 130(1-2):45-50. doi:10.1016/j.jviromet.2005.06.001.

11. Astuti I, Ysrafil. Severe Acute Respiratory Syndrome Coronavirus 2 (SARS-CoV-2): An overview of viral structure and host response. Diabetes Metab Syndr. 2020; 14:407-412. doi: 10.1016/j.dsx.2020.04.020 [Epub ahead of print].

12. Beniac DR, Andonov A, Grudeski E, Booth TF. Architecture of the SARS coronavirus prefusion spike. Nat Struct Mol Biol. 2006;13(8):751752. doi: $10.1038 / \mathrm{nsmb} 1123$.

13. Walls AC, Structure, Function, and Antigenicity of the SARS-CoV-2 Spike Glycoprotein. Cell. 2020;181(2):281-292. https://doi.org/10.1016/j.cell.2020.02.058.

14. Jaimes JA, André NM, Chappie JS, Millet JK, Whittaker GR. Phylogenetic Analysis and Structural Modeling of SARS-CoV-2 Spike Protein Reveals an Evolutionary Distinct and Proteolytically Sensitive Activation Loop. J Mol Biol. 2020. A head of print. doi: 10.1016/j.jmb.2020.04.009.

15. Cascella M, Rajnik M, Cuomo A, Dulebohn SC, Napoli RD. Features, Evaluation and Treatment Coronavirus (COVID-19). Sta tPearls. 2020.

16. Wang Q, Zhang Y, Wu Li, Niu Sh, Song Ch, Zhang Z, Lu G, Qiao Ch, Hu Y, Yuen KY, Wang Q, Zhou H, Yan J, Qi J. Structural and Functional 
Basis of SARS-CoV-2 Entry by Using Human ACE2. Cell. 2020; 181:1-11. https://doi.org/10.1016/j.cell.2020.03.045.

17. Vaccines in Development to Target COVID-19 Disease. Johns Hopkins Center for Health Security, centerforhealthsecurity.org 2020.

18. Chen WH, Strych U, Hotez PJ, Bottazzi ME.The SARS-CoV-2 Vaccine Pipeline: an Overview. Current Tropical Medicine Reports. 2020.https://doi.org/10.1007/s40475-020-00201-6.

19. J\&J working on coronavirus vaccine. The pharma letter. 2020. https:// www.thepharmaletter.com/article/j-j-working-on-coronavirusvaccine. Accessed 28 Feb 2020.

20. ClinicalTrials.gov. National Institutes of Health. https://clinicaltrials.gov/ct2/show/NCT02543567. Accessed February 7, 2020.

21. Cheung E. China coronavirus: Hong Kong researchers have already developed vaccine but need time to test it, expert reveals. South China Morning Post. https://www.scmp.com/news/hong-kong/healthenvironment/article/3047956/china-coronavirus-hongkong-researchershave. Accessed 28 Feb 2020.

22. Shieber J. Codagenix raises $\$ 20$ million for a new flu vaccine and other therapies. Tech Crunch. https://techcrunch.com/2020/01/13/codagenixraises-20-million-for-a-new-flu-vaccine-and-othertherapies/. Accessed 28 Feb 2020.

23. Jiang S, Bottazzi ME, Du L, Lustigman S, Tseng CT, Curti E, et al. Roadmap to developing a recombinant coronavirus $S$ protein receptorbinding domain vaccine for severe acute respiratory syndrome. Expert Rev Vaccines. 2012;11(12):1405-13. https://doi.org/10.1586/erv.12.126.

24. Clover Biopharmaceuticals. Clover initiates development of recombinant subunit-trimer vaccine for Wuhan coronavirus (2019- nCoV). 2020 .

25. Jiang S, Bottazzi ME, Du L, Lustigman S, Tseng CT, Curti E, et al.Roadmap to developing a recombinant coronavirus $\mathrm{S}$ protein receptorbinding domain vaccine for severe acute respiratory syndrome. Expert Rev Vaccines. 2012;11(12):1405-13. https://doi.org/10.1586/erv.12.126.

26. Chen WH, Chag SM, Poongavanam MV, Biter AB, Ewere EA, Rezende W, et al. Optimization of the production process and characterization of the yeast-expressed SARS-CoV recombinant receptorbinding domain (RBD219-N1), a SARS vaccine candidate. J Pharm Sci. 2017;106(8):1961-70. https://doi.org/10.1016/j. xphs.2017.04.037.

27 . Williams JA. Vector design for improved DNA vaccine efficacy, safety and production. Vaccines (Basel) (2013) 1:225- 49.10.3390/vaccines1030225.- Pardi, N., Hogan, M., Porter, F. et al. mRNA vaccines - a new era in vaccinology. Nat Rev Drug Discov. 17, 261-279 (2018). https://doi.org/10.1038/nrd.2017.243.

28. Zhang C, Maruggi G, Shan H, Li J. Advances in mRNA Vaccines for Infectious Diseases. Front. Immunol. 2019; 10:594.https://doi.org/10.3389/fimmu.2019.00594

29. Lee LYY, Izzard L, Hutr AC. A Review of DNA Vaccines Against Influenza. Front Immunol. 2018; 9: 1568. doi: 10.3389/fimmu.2018.01568.

30. Porter KR, Raviprakash K. DNA vaccine delivery and improved immunogenicity. Curr Issues Mol Biol. 2017; 22:12938.10.21775/cimb.022.129.

31. Modjarrad K, Roberts CC, Mills KT, et al. Safety and immunogenicity of an anti-Middle East respiratory syndrome coronavirus DNA vaccine: a phase 1, open-label, single-arm, dose-escalation trial. Lancet Infect Dis. 2019; 19: 1013-1022. DOI:10.1016/S1473-3099(19)30266-X.

32. Yoon I-K, Kim JH. First clinical trial of a MERS coronavirus DNA vaccine. Lancet Infect Dis. 2019; 19: 924-925. doi: 10.1016/S14733099(19)30397-4.

33. Haschke M, Schuster M, Poglitsch M, et al. Pharmacokinetics and pharmacodynamics of recombinant human angiotensin-converting enzyme 2 in healthy human subjects. Clin Pharmacokinet. 2013; 52(9):783-792. doi: 10.1007/s40262-013-0072-7.

34. Khan A, Benthin C, Zeno B, et al. A pilot clinical trial of human recombinant angiotensin-converting enzyme 2 in acute respiratory distress syndrome. Crit Care. 2017;21(1):234. doi: 10.1186/s13054-017-1823-x.

35. Liu C, Zhou Q, Li Y, et al. Research and Development on Therapeutic Agents and Vaccines for COVID-19 and Related Human Coronavirus

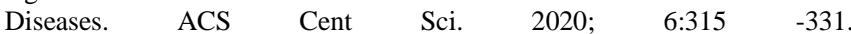
https://dx.doi.org/10.1021/acscentsci.0c00272.

36. Jiang Sh, He Y, Liu Sh. SARS Vaccine Development. Emerg Infect Dis. 2005; 11(7):1016-1020. www.cdc.gov/eid .

37. He Y, Zhou Y, Siddiqui P, Jiang S. Inactivated SARS-CoV vaccine elicits high titers of spike protein-specific antibodies that block receptor binding and virus entry. Biochem Biophys Res Commun. 2004; 325: 44552. DOI: $10.1016 /$ j.bbrc .2004 .10 .052 .

38. Bisht H, Roberts A, Vogel L, et al. Severe acute respiratory syndrome coronavirus spike protein expressed by attenuated vaccinia virus protectively immunizes mice. Proc Natl Acad Sci U S A. 2004;101: 66416. DOI:10.1073/pnas.0401939101. 